Original Research Article

\title{
A questionnaire based study on the knowledge, attitude, and the practice of ecopharmacology among the healthcare professionals in a teaching hospital in India
}

\author{
Manjari Advani, Trupti R. Jadhao*
}

Department of Pharmacology, Lokmanya Tilak Municipal Medical College and General Hospital, Sion, Mumbai, Maharashtra, India

Received: 15 April 2019 Accepted: 13 May 2019

\section{*Correspondence to: \\ Dr. Trupti R. Jadhao, \\ Email: truptijadhao90@ gmail.com}

Copyright: () the author(s), publisher and licensee Medip Academy. This is an openaccess article distributed under the terms of the Creative Commons Attribution NonCommercial License, which permits unrestricted noncommercial use, distribution, and reproduction in any medium, provided the original work is properly cited.

\begin{abstract}
Background: Ecopharmacology which deals with the health hazards posed by discarded or used medicinal products in the environment, is a globally emerging issue. There are guidelines for pharmaceutical waste management (Like GMP and FDA guidelines) for the manufacturing units, pharmacists and consumers. However, it is uncertain whether consumers are aware of it. Before beginning the process of creating awareness, it is first necessary to assess the existing knowledge of the issue in the community. This study was planned to assess the knowledge, attitude and practice (KAP) of ecopharmacology in the medical personnel and students in our institute.

Methods: It was a questionnaire based cross-sectional observational study. Study population included MBBS students, nursing students and resident doctors. Total 500 consenting participants were enrolled and subjected to a structured KAP questionnaire and data was expressed in percentage. Questionnaire consisted of 20 questions out of which 3 were open ended and remaining closed ended.

Results: Present study result showed that $73 \%$ respondents had heard of term ecopharmacology and majority (98\%) felt that it was their responsibility to protect environment from pharmaceutical waste. Responses from $83 \%$ of participants indicated that they were worried about the excess medicines at their homes. $87 \%$ of participants threw it in garbage bin, but $(58 \%)$ were unsure whether their drug disposing method was safe and $25 \%$ knew it was unsafe. Most respondents (94\%) felt that there should be guidelines for safe disposal of expired/unused drug and were enthusiastic about participating in campaign for this issue. Medical personnel also suggested some solutions to deal with this problem.

Conclusions: Awareness and concern regarding the problem is high however in absence of knowledge of methods of safe disposal of unused drug, it is not transforming into safe disposal practices.
\end{abstract}

Keywords: Ecopharmacology, Environmental pharmacology, KAP study, Medicine disposal

\section{INTRODUCTION}

The presence of medicinal products in the environment is a globally emerging issue. Ecopharmacology is the science concerned with the entry of chemicals or drugs into the environment through any route and at any concentration disturbing the balance of ecology (ecosystem), as a consequence. Ecopharmacology is also referred to as environmental pharmacology or ecopharmacostewardship.

The unused or expired medicines can pose a hazard to public safety and to the environment, if they are not safely disposed of, as many drugs lead double lives: one within the body of animal/humans and one in the environment. 
These drugs pass out of the system either as metabolites or unchanged through excretion. These drugs are found in traces in environment, mostly in water. ${ }^{1}$ Various factors for drug entry into environment include consumption, incorrect disposal and through effluents of pharmaceutical companies. There are guidelines for pharmaceutical waste management (Like GMP and FDA guidelines) for the manufacturing units, pharmacists and consumers. ${ }^{2}$ Though the consumption phase is considered to be the biggest contributor to the emissions of medicinal products into the environment, through excretions and incorrect disposal of unused medicines through sinks and toilets, there is unawareness of correct disposal methods. Cocaine, oral contraceptives, carbamazepine and iodine contrast media are some of the examples of drugs found in traces in environment mostly in water. ${ }^{3,4}$ Cocaine has been detected in Po river in Italy and antidepressants, antiepileptics, and lipid-regulating agents (statins) were detected in Niagara river. ${ }^{5,6}$ These drugs then have impact on human beings and animals through environment. The example of this is study from Pakistan which revealed that due to the use of diclofenac in treatment of livestock and consumption of their dead bodies by vultures led to the kidney failures of these vultures. ${ }^{7}$ Similarly in India also the population of vultures declined so drastically that they were declared endangered species. Because of this Government of India banned diclofenac in India for veterinary use. ${ }^{8}$

One of the management strategies which will likely be most effective in mitigating the risks presented by pharmaceuticals in the environment is raising awareness of ecopharmacology among stakeholders. ${ }^{9}$ Before beginning the process of creating awareness, it is first necessary to assess the existing knowledge of the issue in the community. Such studies are few, and hence this study was planned to assess the knowledge, attitude \& practice (KAP) of ecopharmacology in the health care professionals in our institute. Understanding the levels of KAP will enable a more efficient process of creating awareness and seeking solutions.

\section{METHODS}

\section{Study design}

This was a descriptive, cross-sectional survey, conducted through pre-validated structured questionnaire. The study was conducted in our institute over a period of four months between April 2017 to July 2017.

\section{Study population}

The study population was of either gender, which included MBBS students, nursing students and residents doctors from our institute.

\section{Sampling/sample size}

A non-probability sampling technique (convenience method) was employed to reach to the representative population in our institutes. Total of 500 participants were included.

\section{Study instrument}

The questionnaire was designed which consisted of two sections. Section one was about respondent's personal information including gender, age and education. Section two of the questionnaire included questions related to participants knowledge, attitude and practices regarding ecopharmacology. The questionnaire consisted of 20 questions out of which 3 were open ended \& remaining were close ended. For face and content validity, the questionnaire was reviewed by 20 representatives from study population. Following the pilot testing, minor changes were made based on respondents' recommendations.

\section{Data collection method}

The data collectors were trained and prevailed upon to explain the purpose of the study to their respondents prior to administering the survey questionnaire.

Participation in survey was voluntary. The questionnaire was provided in English only.

\section{Data analysis}

All returned questionnaires were double-checked for accuracy and then the collected data were feed into an excel spreadsheet dataset. 486 participants completed the questionnaire satisfactorily and only those were included for evaluation by descriptive manner.

\section{Ethical considerations}

Written informed consent was obtained from all the respondents before the start of the survey. Participation in this research was voluntary. Participant identity was kept confidential. The Ethical Approval was received from institutional ethics committee.

\section{RESULTS}

Out of 500 consenting participants 486 (136 nursing students, 139 M.B.B.S. students and 111 resident doctors) satisfactorily completed the questionnaire and were included for evaluation. The response of participants regarding knowledge of "Ecopharmacology" was as summarised in table no.1. When asked about routes by which drug can pollute environment $>75 \%$ answered soil, water and air. As shown in the Table 1, knowledge and awareness about ecopharmacology in or study was good. Most of the participants knew about this issue through media report and were aware of the hazardous effect of drugs in environment.

Table 2 shows responses to the items intended to measure participants' attitudes towards ecopharmacology. The 
attitude of participants was empathetic. They were aware of issue as well as bothered by excess medicines at home. Very few felt that their methods of drug disposal were safe and most agreed that there was a need for safe drug disposal guidelines for public. The need for drug collection locations and take back schemes for safe drug disposal was accepted by almost all of them. Majority of participants felt it is their responsibility to protect the environment and expressed willingness to participate in campaigns for raising the awareness about this issue.

Table 1: Knowledge about ecopharmacology amongst participants.

\begin{tabular}{|lc|}
\hline Questions & Yes (n=486) \\
\hline Have you heard of the term "Ecopharmacology"? & $73.25 \%$ \\
\hline Do you feel drugs that you consume can cause environmental (water and soil) pollution? & $91.15 \%$ \\
\hline Have you read any media reports regarding effects of drugs pollution on environment? & $84.97 \%$ \\
\hline $\begin{array}{l}\text { Do you think environmental pollution by drugs can be a reason for antibiotic resistance and } \\
\text { cumulative toxicity? }\end{array}$ & $86 \%$ \\
\hline Can the expired/unused medicines which are not properly disposed, pose hazards to public safety? & $96.09 \%$ \\
\hline $\begin{array}{l}\text { Do you know if companies in India have rules and regulations for minimizing the risk due to drug } \\
\text { entry into the environment? }\end{array}$ & $76.13 \%$ \\
\hline
\end{tabular}

Table 2: Attitude of participants towards ecopharmacology.

\begin{tabular}{|ll|}
\hline Question & Yes (n=486) \\
\hline Has it ever bothered you, what to do with excess medicines? & $83.12 \%$ \\
\hline In your opinion are the present methods* safe for disposing medicines? & $17 \%$ \\
\hline Do you think there should be guidelines for public for ecologically safe disposal of drugs? & $94.03 \%$ \\
\hline $\begin{array}{l}\text { Do you think there should be safe medicine disposal locations (e.g. collection boxes for unused } \\
\text { drug in hospitals, pharmacies in city)? }\end{array}$ & $92.18 \%$ \\
\hline Do you think manufactures and pharmacies should have drug take back schemes? & $97.94 \%$ \\
\hline Will you participate in activities like campaign for this issue? & $94.23 \%$ \\
\hline Do you feel it's your responsibility to protect environment from the pharmaceutical waste? & $97.73 \%$ \\
\hline
\end{tabular}

Note:*- Methods were viz. throwing in garbage, giving it to others, and returning to pharmacy.

Table 3: The practices of participants about ecopharmacology.

Questions

Do you buy drugs in bulk for family members?

Do you remove he drug from its container before throwing in the garbage?

Do you pour leftover syrup/lotion from the bottle in the wash basin?
Yes $(\mathbf{n}=486)$

$51.02 \%$

$18 \%$

$18 \%$

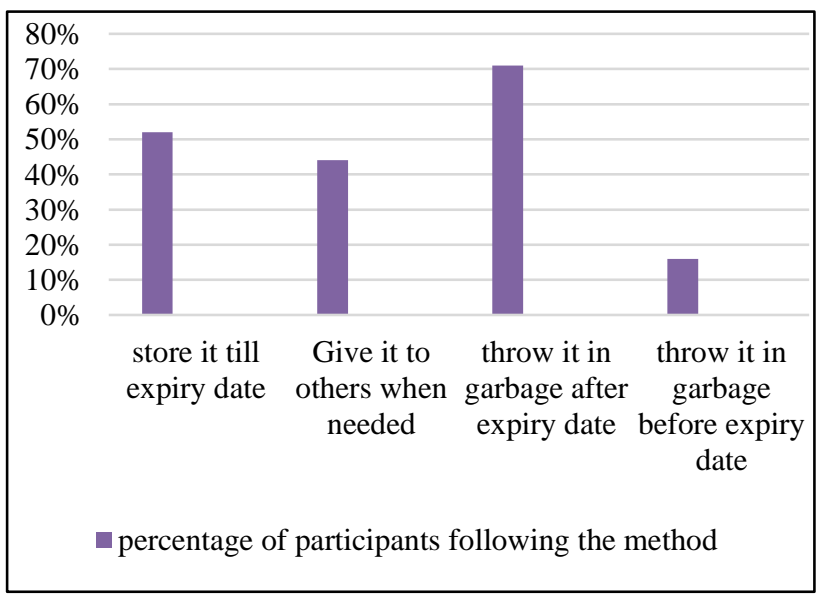

Figure 1: Fate of unused medicines.
As shown in Table 3, half of the participants practice purchasing the medicines in bulk. Most common medicines left unused at home were paracetamol and antibiotics. $64.19 \%$ of respondents said that unused medicines were in tablet form, $25.10 \%$ in syrup form and $10.69 \%$ in ointment form. Fate of unused drugs is shown Figure 1.

\section{Participants suggested the following}

- Package inserts or labels containing information about safe disposal of that medicine.

- Different colored dustbins for medicinal disposal at certain locations.

- PHCs/Government hospitals should be the center for returning the unused medicines and from there drugs should be disposed safely. 


\section{DISCUSSION}

Authors observed that the knowledge of ecopharmacology in the study group was satisfactory and majority of them had read the media reports regarding it. Most of our participants $(91.15 \%)$ felt that the drugs they consume could cause environmental pollution and were aware of the hazardous environmental and health impact of improper disposal of unused and expired medicines. Studies of drug disposal practices in university students from Kabul and general population from Serbia have also reported of awareness on this issue but lesser than our study. ${ }^{10,11}$

In present study $86 \%$ of the participants agreed that environmental pollution by drugs can be reason for antibiotic resistance and cumulative drug toxicity. A wide range of antibacterials have been observed in waters and soils and many of these persist for some time. Subtle effects of pharmaceutical compounds on aquatic and terrestrial organisms have been reported. One such study indicated that increased amount of pig manure resulted in increased levels of tetracycline resistance in the soil, which could pose a threat to human and animal health. ${ }^{12}$ According to the media report, antibiotics we throw away may be breeding superbugs. Researchers found that at entry of Yamuna river near Wazirabad in north Delhi, concentrations of fluconazole (antifungal), ofloxacin (antibiotic) and ibuprofen (painkiller) were less than 0.05 micrograms per liter. At the Yamuna's exit near Okhla barrage, the concentrations of fluconazole, ofloxacin and ibuprofen increased by 80,96 and 50 times, respectively. ${ }^{13}$

Present study participants were concerned about the disposal of the excess medicines at home but were unaware of safe disposal methods. There are WHO guidelines for 'safe disposal of unwanted pharmaceuticals'. ${ }^{14}$ In addition to that; National Formulary of India also has an appendix 7 regarding the methods of disposal of unused/expired pharmaceutical products.2 Good Manufacturing Practices (GMP) laid down in Schedule $M$ of the 'Drugs and Cosmetics Rules, 1945' also give the requirements for disposal of waste including the rejected drugs. ${ }^{15}$ These guidelines are useful for wholesale chemists, clinics, hospitals and pharmaceutical manufacturers but not for general consumers. This is a finding reflected in our study where $96 \%$ of our participants agreed regarding the need for guidelines for ecologically safe disposal of drugs by people.

Responses from $87 \%$ showed that they throw away the excess medicines in the household trash. This is similar to findings of the study an Asian study in which most of the respondents $(234 / 301 ; 77.7 \%)$ were throwing the expired medicine in household trash while $21.3 \%$ of the respondents returned unused and expired pharmaceuticals to medical stores. Returning expired and unused medicines to medical stores is community practice in the USA (23\%) and UK $(22 \%){ }^{10,16,17}$ Whereas in present study, none of the participants have done this. Another method of disposal observed in our study was that $44 \%$ of the participants shared their excess medications with other when indicated. Few other studies have also reported the practice of sharing of medications albeit in $1-2 \%$ of the study population, probably because they were from non-medical background. ${ }^{10,18,19}$ Total $18 \%$ of studied participants practiced pouring of liquid medication in the wash basin. Similar practices were reported in studies from Kuwait, UK and USA. ${ }^{17,20}$ According to standard guidelines also small quantity liquid medications should be diluted with water and drained. ${ }^{2}$

Drugs or their metabolites also find their path to enter the food chain through this route. ${ }^{21}$ Therefore, studies have been conducted throughout the world about this issue to find the policy solutions. Indian government also needs to be proactive to launch feasible expired pharmaceutical collection programs, such as Francisco's Safe Medicine Disposal program, Dispose a Med program, Chemical Control Program, Sharps Waste Disposal Program Expired medications drop-off operation in California USA. ${ }^{22}$ Medications Return Program or Take-back programs in Canada and Meds Disposal in Europe. ${ }^{23-25}$ The Nebraska Medication Education for Disposal Strategies (MEDS) has suggested the "golden standard" for safe, legal, environmentally sound disposal, to put tamper resistant boxes in pharmacies that will allow consumers to bring medicines back to knowledgeable pharmacists. ${ }^{10}$ In Sweden and Korea, more people return unused medicines to a pharmacy for correct disposal, as they have realized the environmental concerns posed by expired medicines. ${ }^{26,27}$

The proper and best option for the safe disposal of pharmaceutical waste is incineration which requires third party intervention for the collection of unwanted medicines. ${ }^{28}$ For example, in Australia, the return of unused medication service runs a medication collection and destruction service through community pharmacies which employ a high-temperature incineration method approved by the US Environmental Protection Agency. ${ }^{29}$ In Taiwan, an educational pharmacist intervention booklet has been designed to teach their customers in how to use and store the medications properly. ${ }^{30}$ Many of the big Pharmaceuticals are supporting the take-back schemes worldwide, India needs to be the part of it. Participants, in present study have also suggested the same.

The following combinations of management strategies will most likely be effective in mitigating the risks presented by pharmaceuticals in the environment

- Rational drug use

- Pharmaceutical-return programs

- $\quad$ Raising awareness among stakeholders, i.e., patients, doctors, nurses, and pharmacists

- Advanced effluent treatment with sophisticated sewage treatment plants and waste water treatment plants 
- Incentives for the development of "green" pharmaceuticals, and improved regulations and guidance on pharmaceutical waste management.

There is evidence that targeted campaigns can influence the way patients handle unwanted medications. ${ }^{16}$ It was observed that in USA only $2 \%$ people returned unused medicines to USA pharmacies; 10 years later the percentage of people returning unused medicines to pharmacy raised to $23 \% .^{17,30,31}$ Careful and proper disposal of medications can help to decrease environmental load of drugs. All multidisciplinary stake holders will need to work together hand in hand to reduce burden of unused and expired medicine on ecosystem. Proper waste management strategy is needed to ensure health and environmental safety. ${ }^{2}$

From the questionnaire it was observed that the knowledge of medical personnel and student about ecopharmacology and problems associated with it was good. Attitude of medical personnel and students was also very empathetic, but this is not transforming into practices. Gaps exist in knowledge and practices, therefore robust, safe and costeffective pharmaceutical waste management program supported with media campaign is needed. Healthcare practitioners and community pharmacists should be trained and then offer training to educate customers on standard medicine disposal practices.

Funding: No funding sources Conflict of interest: None declared

Ethical approval: The study was approved by the Institutional Ethics Committee (IEC/50/170)

\section{REFERENCES}

1. Joss A, Zabczynski S, Gobel A, Hoffmann B, Loffl er D, McArdell CS, et al. Biological degradation of pharmaceuticals in municipal wastewater treatment: Proposing a classifi cation scheme. Water Res. 2006;40:1686-96.

2. Kadam A, Patil S, Patil S, Tumkur A. Pharmaceutical Waste Management An Overview. Indian J Pharma Pract. 2016;9(1):2-8.

3. Zuccato E, Chiabrando C, Castiglioni S, Calamari D, Bagnati R, Schiarea S, Fanelli R. Cocaine in surface waters: a new evidence-based tool to monitor community drug abuse. Env Health. 2005;4(1):14.

4. Kolpin DW, Furlong ET, Meyer MT, Thurman EM, Zaugg SD, Barber LB et al. Pharmaceuticals, hormones, and other organic wastewater contaminants in U.S. streams, 1999-2000: A national reconnaissance. Env Sci Technol. 2002;36:1202-11.

5. Castiglioni S, Fanelli R, Calamari D, Bagnati R ZE. Methodological approaches for studying pharmaceuticals in the environment by comparing predicted and measured concentrations in River Po, Italy. Regul Toxicol Pharmacol. 2004;39:25-32.

6. Heberer T. Occurrence, fate, and removal of pharmaceuticals residues in the aquatic environment:
A review of recent research data. Toxicol Lett. 2002;131:5-17.

7. Oaks JL, Gilbert M, Virani MZ, Watson RT, Meteyer $\mathrm{CU}$, Rideout BA, et al. Diclofenac residues as the cause of vulture population decline in Pakistan. Nature. 2004;427:630-3.

8. Taggart MA, Senacha KR, Green RE, Jhala YV RA. Diclofenac residues in carcasses of domestic ungulates available to vultures in India. Env Int. 2007;33:75965 .

9. Ocean A, Take D. Ecopharmacology: an issue that needs urgent action. Int J Basic Clin Pharmacol. 2016;5(5):2288-9.

10. Bashaar M, Thawani V, Hassali MA, Saleem F. Disposal practices of unused and expired pharmaceuticals among general public in Kabul. BMC Public Health. 2017;17(1):45.

11. Seehusen D, Edwards J. Patient Practices and Beliefs Concerning Disposal of Medications. J Am Board Fam Med. 2006;19(6):542-7.

12. Boxall ABA. The environmental side effects of medication. EMBO Rep. 2004 Dec; 5(12): 1110-6.

13. The times of India. Antibiotics you throw away may be breeding superbugs. 2018;3. Available at: https://timesofindia.indiatimes.com/india/antibioticsyou-throw-away-may-be-breedingsuperbugs/articleshowprint/65585501.cms. (Accessed on 26-3-19).

14. Guidelines for Safe Disposal of Unwanted Pharmaceuticals in and after Emergencies. 1999;(19):301-54. Available at: https://www.who.int/water_sanitation_health/emerge ncies/unwantpharm.pdf. (Accessed on 26-3-19).

15. Press Information Bureau Government of India Ministry of Health and Family Welfare. 2019;2-3. Available at: http://www.pib.nic.in/newsite/PrintRelease.aspx?reli $\mathrm{d}=178039$ url for ref 15. (Accessed on 26-3-19).

16. Azad MA, Ansary RH, Akhter A, Al-Mamun SM, Uddin M, Rahman MM. Disposal practice for unused medications among the students of the International Islamic University Malaysia. J App Pharmaceut Sci. 2012;2(7):101-6.

17. Kuspis D KE. What happens to expired medications? A survey of community medication disposal. Vet Hum Toxicol. 1996;38(1):48-9.

18. Kusturica MP, Sabo A, Tomic Z, Horvat O ŠZ. Storage and disposal of unused medications: knowledge, behavior, and attitudes among Serbian people. Int J Clin Pharm. 2012;34(4):604-10.

19. Ellis J, Mullan J. Prescription medication borrowing and sharing: risk factors and management. Aust Fam Physician. 2009;38(10):816.

20. Abahussain EA, Ball DE. Disposal of unwanted medicines from households in Kuwait. Pharmacy World Sci. 2007;29(4):368-73.

21. De Bolle L, Mehuys E, Adriaens E, Remon JP, Van Bortel L, Christiaens T. Home medication cabinets and self-medication: a source of potential health threats?. Ann Pharmacothe. 2008;42(4):572-9. 
22. Glassmeyer ST, Hinchey EK, Boehme SE, Daughton CG, Ruhoy IS, Conerly O, et al. Disposal practices for unwanted residential medications in the United States. Env Int. 2009;35(3):566-72.

23. Returning unused and expired medications in British Columbia. Health Products Stewardship Association. Available at: http://www.healthsteward. ca/returns/british-columbia. Accessed 28 September 2016.

24. Macarthur D. Any old drugs? Two schemes for the disposal of unwanted medicines in Europe. Pharm J. 2000;264(70):223-4.

25. Lubick N. Drugs in the environment: do pharmaceutical take-back programs make a difference? Env Heal Perspect. 118(5):A210.

26. Persson M, Sabelström E GB. Handling of unused prescription drugs-knowledge, behaviour and attitude among Swedish people. Env Int. 2009;35(5):771-4.

27. Hwang BD. Storage and disposal of unused medications for housewives in the Busan Metropolitan
City. Korean J Health Service Managem. 2013;7(2):69-79.

28. Smith CA. Managing pharmaceutical waste. J Pharm Soc Wis. 2002;5:17-22.

29. Tong AY, Peake BM BR. Disposal practices for unused medications around the world. Env Int. 2011;37(1):292-8

30. Chien HY, Ko JJ, Chen YC, Weng SH, Yang WC, Chang YC, Liu HP. Study of medication waste in Taiwan. J Experimen Clin Med. 2013;5(2):69-72.

31. Seehusen DA, Edwards J. Patient practices and beliefs concerning disposal of medications. J Am Board Fam Med. 2006;19(6):542-7.

Cite this article as: Advani M, Jadhao TR. A questionnaire based study on the knowledge, attitude, and the practice of ecopharmacology among the healthcare professionals in a teaching hospital in India. Int J Basic Clin Pharmacol 2019;8:1413-8. 